Basic Health Sciences

Poster

Abstract ID: 146

\title{
Kappa antagonist to prevent drug relapse: Does stage in addiction cycle matter?
}

Irna Elina Ridzwan ${ }^{\mathrm{a}} \mid$ Muhammad Harith Zulkifli $^{\mathrm{a}} \mid$ Nur Syafinaz Wasli ${ }^{\mathrm{b}} \mid$ Syed Mohd Syahmi Syd Mohmad Faudzic

${ }^{a}$ Department of Pharmaceutical Chemistry, Kulliyyah of Pharmacy, International Islamic University Malaysia

${ }^{b}$ Department of Basic Medical Sciences, Kulliyyah of Pharmacy, International Islamic University Malaysia

Department of Pharmacy Practice, Kulliyyah of Pharmacy, International Islamic University Malaysia

Introduction: An upregulation of the kappa opioid receptor (KOR) system during drug preoccupation stage in addiction cycle will cause dysphoria among addicts which can lead to relapse. Therefore, KOR antagonism treatment might hold the key to prevent relapse. In this study, we aim to identify the exact addiction's stage in which KOR antagonist can be given. Methods: Using a conditioned place preference (CPP) model, adult male Swiss albino mice were divided into two major groups. The first group received treatment at the initial stage of morphine withdrawal $(7.5 \mathrm{mg} / \mathrm{kg}$, i.p) while the second group received treatment after complete abstinence was achieved. Each major groups were further divided into two treatment groups $(n=8-12)$, either received a functional KOR antagonist $(0.3 \mathrm{mg} / \mathrm{kg}$ buprenorphine/ $1 \mathrm{mg} / \mathrm{kg}$ naltrexone combination, i.p) or a selective KOR antagonist $(10 \mathrm{mg} / \mathrm{kg}$ nor-BNI, i.p) prior to morphine priming $(2.5 \mathrm{mg} / \mathrm{kg}$, i.p). All data were analyzed using paired sample t-test. Results: The results showed that relapse was successfully attenuated in the groups that received KOR antagonists only after complete abstinence was successfully achieved (not significantly different from their baseline). However, the mice developed unusual sign of behavior sensitization (intermittent freezing, licking) when buprenorphine/naltrexone combination was given at initial stage of withdrawal. Conclusions: Our initial findings suggest that KOR antagonism might be beneficial only after the addicts achieved complete abstinence to prevent future druginduced relapse. Brain study should be conducted to explain the unusual behavior seen when the drug intervention is given at an earlier stage of withdrawal.

KEYWORDS: drug relapse, kappa antagonist, morphine 